\title{
Prediction of silage digestibility by near infrared reflectance spectroscopy
}

\author{
X. Liu ${ }^{1}$, L. Han ${ }^{1}$, Z. Yang and Ch. Xu \\ College of Engineering, China Agricultural University \\ Beijing 100083, P.R. China
}

(Received 24 January 2008; revised version 25 July 2008; accepted 27 October 2008)

\begin{abstract}
A total of 142 silage samples were used to evaluate the ability of near infrared reflectance spectroscopy (NIRS) to predict dry matter (DM) and neutral detergent fibre (NDF) digestibility. Three techniques, Partial Least Square (PLS), Principal Component Regression (PCR) and Multivariate Linear Regression (MLR), and a series of mathematical treatments were applied to establish the NIRS calibrations. The F-test and T-test of correlativity between reference and NIRS values of silage samples in validation set were carried out to verify the models. Results showed the PLS technique gave the best prediction and calibrations, and that the calibrations developed from the combination of smooth and first-order derivative treatment were largely acceptable. The prediction of DM digestibility of dried samples was good with the determination coefficient of validation $\left(\mathrm{r}^{2}\right)$ being greater than 0.80 . The prediction of dried samples was better than that of fresh samples. The relative standard deviation (RSD) values of DM digestibility for dried and fresh samples were 8.25 and $11.26 \%$, respectively. As for NDF digestibility, the RSD values were higher, being of 22.87 and $23.50 \%$ for dried and fresh samples, respectively.
\end{abstract}

KEY WORDS: silage, NIRS, digestibility, regression techniques

\section{INTRODUCTION}

Silage constitutes the major conserved feed for ruminants in North China with whole plant maize or maize stalk being the most important material besides straws of rice, wheat and sorghum. Good knowledge of the digestibility of nutritional components of silage is important in both research and farm advisory work. The most conventional procedure is the determination of in vivo digestibility, but it is

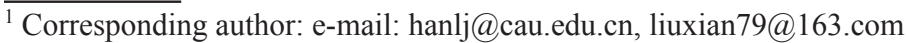


both laborious and expensive. Therefore, techniques have been developed, such as a method based on chemical composition (Clancy and Wilson, 1966), the gas production method (Menke et al., 1979), the nylon bag technique (Mehrez and Ørskov, 1977), the rumen fluid in vitro procedure (Tilley and Terry, 1963) and an enzymatic in vitro technique (De Boever et al., 1986). Amongst them, the twostage technique of Tilley and Terry (1963) is popular for its good prediction. But, it is also time consuming and always involves operations fixing fistula, which is not animal-friendly. The physical method of near infrared spectroscopy (NIRS) is promising and many researchers used this technique to predict the digestibility of forages or silages ( Norris et al., 1976; Melchinger et al., 1986; Barber et al., 1990; Baker et al., 1994; Van Waes et al., 1997; De Boever et al., 2002). Relative to conventional laboratory procedures, NIRS offers advantages of simplicity, speed, reduced chemical waste, and more cost-effective predictions.

However most of the published research with NIRS is about the prediction of organic matter digestibility in dried, ground samples. Previously we have studied the use of NIRS for predicting chemical compositions of silage (Liu and Han, 2006), now our objective was to investigate the possibility of NIRS to predict the dry matter (DM) and neutral detergent fibre (NDF) digestibility of silage, and to establish NIRS calibrations on dried ground, as well as on fresh coarse samples.

\section{MATERIAL AND METHODS}

\section{Silages collection and preparation}

The present study involved 142 silages sampled from cattle farms and laboratories of six provinces in China during June 2003 - December 2005, of which 67 were whole plant maize silages, 58 were maize stalk silages, and 17 were samples of either rice, wheat or sorghum silage. These samples were ensiling occurred with or without silage additives (lactobacillus, enzyme, molasses and formic acid) by different techniques (ensiling with silos, polyethylene bags and barrels). All the silages had a particle size between 2 and $10 \mathrm{~cm}$.

The samples were frozen on the day of collection and stored until analysed. Prior to NIRS scanning of the fresh samples, the silages were thawed overnight at $4^{\circ} \mathrm{C}$ and cut in pieces of 2 to $4 \mathrm{~cm}$ in order to be packed easily in the sample cell. A subsample of each silage was dried in a forced-air oven at $65^{\circ} \mathrm{C}$ for $48 \mathrm{~h}$ and milled to pass a $1 \mathrm{~mm}$ screen for NIRS scanning of dried samples and subsequent in vitro digestibility analysis. 


\section{NIR scanning}

All work was performed on a NIRS system SPECTRUM ONE NTS (PerkinElmer, New Jersey, USA). The fresh silage samples were packed in a rotating circular quartz cell of $10 \mathrm{~cm}$ diameter. The dried and ground samples were scanned in small cups with a quartz window of $4 \mathrm{~cm}$ diameter. Each of the 142 silage samples was scanned three times as $\log 1 / \mathrm{R}$ over the wavelength range from 1100 to $2500 \mathrm{~nm}$ at $2 \mathrm{~nm}$ intervals and the average spectrum was recorded.

\section{Wet chemical analysis}

The digestibility was determined with rumen fluid from four fistulated cattle, according to the classical two-stage method of Tilley and Terry (1963). DM was analysed according to AOAC (1990). NDF was analysed following the method of Van Soest et al. (1991). All analyses were run in duplicate, and the average results were recorded.

\section{Statistical analysis}

The partial least square (PLS), principal component regression (PCR) and multivariate linear regression (MLR) applied on the whole database without mathematical treatment were carried out with TQ software (Thermo Nicolet, USA). The technique resulting in the lowest standard error of cross-validation (SECV) and the highest determination coefficient of cross-validation $\left(\mathrm{R}_{\mathrm{cv}}^{2}\right)$ was chosen. The mathematical treatment of the spectra data was performed using Spectrum QUANT+ software (PerkinElmer, New Jersey, USA). NIRS calibrations were developed by means of the chosen regression technique. The following mathematical treatments were applied separately and simultaneously and then compared for choosing the best treatment combination: smoothing, derivative, standard normal variate (SNV) and detrend and multiplicative scatter correction (MSC). Cross-validation was carried out to select the optimal number of terms in the equation, so avoiding overfitting. The data set was sorted by the digestibility and from every four samples one was taken out for validation sample, so the data set was divided into a calibration set of 107 samples and a validation set of 35 samples. The mathematical treatment resulting in the lowest standard error of cross-validation (SECV) on the whole data set for each parameter was applied to the calibration set, and the resultant equation was used to predict the validation set. The following statistical parameters were considered: the determination coefficient of calibration $\left(\mathrm{R}^{2}\right)$, the standard error of calibration (SEC), the determination coefficient of validation $\left(\mathrm{r}^{2}\right)$, the standard error of prediction (SEP), 
Bias and the relative standard deviation (RSD), RSD is the ratio of SEP and $\bar{y}_{\mathrm{v}}$, while $\bar{y}_{\mathrm{v}}$ is the average of reference values of validation set. The F-test and t-test (statistical significance test) of correlation between reference values and NIRS values of silage samples in the validation set were also carried out to evaluate the NIRS models.

For F-test:

$$
\begin{gathered}
F=\frac{\left(n_{v}-2\right) \hat{b} \sum_{i=1}^{n_{v}}\left(y_{i}-\bar{y}\right)\left(z_{i}-\bar{z}\right)}{\sum_{i=1}^{n_{v}}\left[y_{i}-\left(\hat{a}+\hat{b} z_{i}\right)\right]^{2}} \\
\bar{y}=\frac{1}{n_{v}} \sum_{i=1}^{n_{v}} y_{i} \quad \bar{z}=\frac{1}{n_{v}} \sum_{i=1}^{n_{v}} z_{i} \quad \hat{a}=\bar{y}-\hat{b} \bar{z} \quad \hat{b}=\frac{\sum_{i=1}^{n_{v}} z_{i} y_{i}-n_{v} \bar{z} \bar{y}}{\sum_{i=1}^{n_{v}} z_{i}^{2}-n_{v} \bar{z}^{2}}
\end{gathered}
$$

For t-test:

$$
\begin{aligned}
t_{a} & =\left[\frac{n_{v}\left(n_{v}-2\right) \sum_{i=1}^{n_{v}}\left(z_{i}-\bar{z}\right)^{2}}{\sum_{i=1}^{n_{v}} z_{i}^{2}}\right]^{\frac{1}{2}} \frac{\hat{a}-0}{\sqrt{\sum_{i=1}^{n_{v}}\left(y_{i}-\hat{a}-\hat{b} z_{i}\right)^{2}}} \\
t_{b} & =\left[\frac{\left(n_{v}-2\right) \sum_{i=1}^{n_{v}}\left(z_{i}-\bar{z}\right)^{2}}{\sum_{i=1}^{n_{v}}\left(y_{i}-\hat{a}-\hat{b} z_{i}\right)^{2}}\right]^{\frac{1}{2}}(\hat{b}-1)
\end{aligned}
$$

$n_{v}$ is the number of samples, $y_{i}$ is the reference value $\left(i=1,2, \ldots, n_{v}\right), z_{i}$ is the NIRS value $\left(i=1,2, \ldots, n_{v}\right)$, if $F>F_{0.01}\left(1, n_{v}-2\right),\left|\mathrm{t}_{\mathrm{a}}\right|<t_{0.05}\left(n_{v}-2\right)$ and $\left|\mathrm{t}_{\mathrm{b}}\right|<t_{0.05}\left(n_{v}-2\right)$, the notable correlation between reference values and NIRS values were validated.

\section{RESULTS AND DISCUSSIONS}

NIR spectra of silages. A group of peaks were observed in the spectra of dried samples, which provided abundant information for calibrations. For fresh coarse samples, there were two apparent peaks at about 1440 and $1940 \mathrm{~nm}$, which may be attributed to the absorption by water in fresh silage samples. It was concluded that the physical state affected the NIR spectra of silage.

Silage composition. The number of samples, mean, minimum, maximum value and standard deviation (SD) of the digestibility of DM and NDF for the calibration and the validation set are summarized in Table 1 . 
Table 1. Digestibility of silage samples used for calibration and validation

\begin{tabular}{|c|c|c|c|c|c|c|c|c|c|c|}
\hline \multirow{3}{*}{$\begin{array}{l}\text { Digestibility } \\
\%\end{array}$} & \multicolumn{5}{|c|}{ Calibration } & \multicolumn{5}{|c|}{ Validation } \\
\hline & \multirow{2}{*}{$\begin{array}{c}\text { number } \\
\text { of samples }\end{array}$} & \multicolumn{4}{|c|}{ digestibility } & \multirow{2}{*}{$\begin{array}{r}\text { number } \\
\text { of samples }\end{array}$} & \multicolumn{4}{|c|}{ digestibility } \\
\hline & & mean & $\min$ & $\max$ & SD & & mean & $\min$ & $\max$ & $\mathrm{SD}$ \\
\hline $\mathrm{DM}$ & 107 & 51.7 & 21.7 & 75.4 & 10.6 & 35 & 51.5 & 25.0 & 68.2 & 10.1 \\
\hline NDF & 107 & 23.8 & 7.0 & 48.3 & 8.5 & 35 & 24.1 & 9.5 & 47.5 & 8.7 \\
\hline
\end{tabular}

DM - dry matter; NDF - neutral detergent fibre; mean - mean value; min - minimum value; max -maximum value; $\mathrm{SD}$ - standard deviation

All the data is on a dry weight basis. The silage samples collected for this study showed a wide variation in their digestibility of DM and NDF, as would be expected for a broad prediction.

Regression technique and mathematical treatments. Table 2 shows the results of parameter digestibility for PLS, PCR and MLR regression techniques. The effects of regression technique on the accuracy of digestibility of dried samples were relatively similar to that for fresh samples. It was evident that the PLS technique produced the best results for the parameter digestibility, having the lowest SECV and the highest $\mathrm{R}_{\mathrm{cv}}^{2}$. Although the spectral information for PCR is identical as for PLS, the latter is more accurate, whereas MLR comprises only information of a few wavelengths. This observation was consistent with other reports (Goedhart, 1990; Baker et al., 1994; Gordon et al., 1998).

Table 2. The statistics for different regression techniques

\begin{tabular}{lcccccc}
\hline \multirow{2}{*}{$\begin{array}{l}\text { Digestibility } \\
\%\end{array}$} & \multirow{2}{*}{ Techniques } & \multicolumn{2}{c}{ Dried samples } & & \multicolumn{2}{c}{ Fresh samples } \\
\cline { 3 - 4 } \cline { 6 - 7 } & & $\mathrm{R}_{\mathrm{cv}}^{2}$ & SECV & & $\mathrm{R}_{\mathrm{cv}}^{2}$ & SECV \\
\hline \multirow{3}{*}{$\mathrm{DM}$} & PLS & 0.78 & 4.9 & & 0.53 & 7.8 \\
& PCR & 0.75 & 5.2 & & 0.51 & 7.9 \\
& MLR & 0.64 & 6.3 & & 0.24 & 9.8 \\
\multirow{2}{*}{ NDF } & PLS & 0.48 & 6.4 & & 0.35 & 7.8 \\
& PCR & 0.45 & 6.5 & & 0.34 & 7.9 \\
& MLR & 0.33 & 7.2 & & 0.31 & 8.1 \\
\hline
\end{tabular}

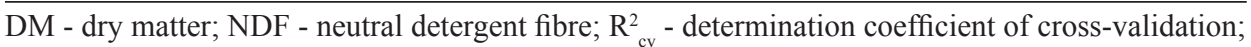
SECV - standard error of cross-validation

The statistics developed from PLS technique for different mathematics treatments are presented in Table 3.

Better results were obtained for the first-order derivative treatment than the second-order derivative. Although the $\mathrm{R}_{\mathrm{cv}}^{2}$ produced by the second-order derivative was greater than that of the first-order derivative, its SECV was also greater, and this was mostly the results of over fitting. The SNV and MSC treatment always provided similar results, where the combination of smooth and firstorder derivative approved statistics mostly. For dried samples of silage, the best 
Table 3. The statistics for different mathematical treatments

\begin{tabular}{|c|c|c|c|c|c|c|c|c|}
\hline \multirow{3}{*}{$\begin{array}{l}\text { Mathematical } \\
\text { treatment }\end{array}$} & \multicolumn{4}{|c|}{ Dried samples digestibility } & \multicolumn{4}{|c|}{ Fresh samples digestibility } \\
\hline & \multicolumn{2}{|c|}{ DM } & \multicolumn{2}{|c|}{$\mathrm{NDF}$} & \multicolumn{2}{|c|}{ DM } & \multicolumn{2}{|c|}{$\mathrm{NDF}$} \\
\hline & $\mathrm{R}_{\mathrm{cv}}^{2}$ & SECV & $\mathrm{R}_{\mathrm{cv}}^{2}$ & SECV & $\mathrm{R}_{\mathrm{cv}}^{2}$ & SECV & $\mathrm{R}_{\mathrm{cv}}^{2}$ & SECV \\
\hline $1 \mathrm{D}$ & 0.84 & 4.2 & 0.55 & 5.8 & 0.69 & 6.5 & 0.57 & 6.5 \\
\hline $2 \mathrm{D}$ & 0.90 & 6.9 & 0.87 & 6.4 & 0.46 & 8.2 & 0.34 & 8.0 \\
\hline SNV & 0.77 & 5.1 & 0.58 & 5.6 & 0.64 & 6.9 & 0.39 & 7.5 \\
\hline MSC & 0.76 & 5.2 & 0.58 & 5.6 & 0.62 & 6.9 & 0.34 & 7.8 \\
\hline $\mathrm{SNV}+1 \mathrm{D}$ & 0.78 & 5.0 & 0.66 & 5.1 & 0.71 & 6.1 & 0.72 & 5.2 \\
\hline $\mathrm{MSC}+1 \mathrm{D}$ & 0.76 & 5.0 & 0.58 & 5.3 & 0.64 & 6.6 & 0.50 & 6.8 \\
\hline $1,5,5$ & 0.84 & 4.2 & 0.77 & 4.9 & 0.71 & 6.1 & 0.72 & 5.3 \\
\hline $1,5,9$ & 0.84 & 4.3 & 0.77 & 4.9 & 0.71 & 6.1 & 0.72 & 5.1 \\
\hline $1,5,13$ & 0.84 & 4.3 & 0.77 & 4.9 & 0.71 & 6.1 & 0.73 & 4.9 \\
\hline
\end{tabular}

DM - dry matter; NDF - neutral detergent fibre; mathematical treatment (-, -, -) - pre-treatment of the NIR spectra, where the first number is the derivative order, the second number is the gap between points used to calculate the difference, and the last one is the number of data points used to smooth the data; SNV - standard normal variate; MSC - multiplicative scatter correction; 1D - first-order derivative; $2 \mathrm{D}$ - second-order derivative; $\mathrm{R}_{\mathrm{cv}}^{2}$ - determination coefficient of cross-validation; SECV - standard error of cross-validation

mathematical treatment was 1, 5, 5 for both DM and NDF digestibility (where the first number is the derivative order, the second number is the gap between points used to calculate the difference, and the last one is the number of data points used to smooth the data), while the corresponding best mathematical treatments were $1,5,9$ and $1,5,13$ for fresh samples.

NIRS predictions. The NIRS predictions were carried out by PLS technique with the selected mathematical treatments. The calibration and validation statistics for the digestibility of dried and fresh silage samples are given in Tables 4 and 5, respectively.

Table 4. The calibration statistics for the digestibility of silage samples

\begin{tabular}{|c|c|c|c|c|c|c|c|c|}
\hline \multirow{2}{*}{$\begin{array}{l}\text { Digestibility } \\
\%\end{array}$} & \multicolumn{4}{|c|}{ Dried samples } & \multicolumn{4}{|c|}{ Fresh samples } \\
\hline & $\begin{array}{c}\text { mathematical } \\
\text { treatment }\end{array}$ & $\mathrm{T}$ & $\mathrm{R}^{2}$ & SEC & $\begin{array}{c}\text { mathematcal } \\
\text { treatment }\end{array}$ & $\mathrm{T}$ & $\mathrm{R}^{2}$ & SEC \\
\hline $\mathrm{DM}$ & $1,5,5$ & 7 & 0.89 & 3.7 & $1,5,9$ & 7 & 0.78 & 5.3 \\
\hline NDF & $1,5,5$ & 7 & 0.77 & 4.2 & $1,5,13$ & 8 & 0.78 & 4.6 \\
\hline
\end{tabular}

DM - dry matter; NDF - neutral detergent fibre; mathematical treatment (-, -, -) - pre-treatment of the NIR spectra, where the first number is the derivative order, the second number is the gap between points used to calculate the difference, and the last one is the number of data points used to smooth the data; $\mathrm{R}^{2}$ - determination coefficient of calibration; $\mathrm{SEC}$ - standard error of calibration; $\mathrm{T}$ - number of terms in the equation

Results showed that DM digestibility of dried samples produced good predictions, with $\mathrm{R}^{2}$ and $\mathrm{r}^{2}$ greater than 0.8 . The prediction of dried samples was better than that of fresh samples, where the $\mathrm{R}^{2}$ and $\mathrm{r}^{2}$ were all greater, and the SEC 
Table 5. The validation statistics for the digestibility of silage samples

\begin{tabular}{|c|c|c|c|c|c|c|c|c|}
\hline \multirow{2}{*}{$\begin{array}{l}\text { Digestibility } \\
\%\end{array}$} & \multicolumn{4}{|c|}{ Dried samples } & \multicolumn{4}{|c|}{ Fresh samples } \\
\hline & $r^{2}$ & SEP & Bias & RSD & $\mathrm{r}^{2}$ & SEP & Bias & RSD \\
\hline DM & 0.83 & 4.2 & -1.01 & 8.25 & 0.67 & 6.0 & -0.57 & 11.26 \\
\hline NDF & 0.66 & 5.5 & 1.76 & 22.87 & 0.62 & 5.8 & 0.53 & 23.50 \\
\hline
\end{tabular}

DM - dry matter; NDF - neutral detergent fibre; $r^{2}$ - determination coefficient of validation; SEP - standard error of prediction; RSD - relative standard deviation of validation

and SEP were all lower than that of fresh samples. This maybe attributed to the good homogeneity of dried and ground samples, which was very important for NIRS prediction. The somewhat better results of dried samples could also partly be explained by the fact that dried samples were used for both the determination of in vitro digestibility and NIRS scanning.

For NDF digestibility, the NIRS predictions were less accurate than for DM digestibility. The calibration and validation statistics of dried samples were very similar to that of fresh samples, which suggested that the physical state of silage samples did not affect the accuracy of NIRS analysis on the NDF digestibility.

A number of researchers have studied the accuracy of NIRS for predicting in vitro digestibility in silages (Norris et al., 1976; Moe and Carr, 1985; Barber et al., 1990; Kjos, 1990; Baker et al., 1994; De Boever et al., 1997). The potential of NIRS to predict DM digestibility with dried ground samples have been previously examined by Norris in 1976. In the study of De Boever et al. $(1986,1997)$, NIRS based on dried ground grass silage and maize silage formed the $\mathrm{r}^{2}$ of 0.75 and 0.56 for in vitro OM digestibility, and the SEP of 2.2 and $1.5 \%$, respectively. Gordon et al. (1998) showed that the OM digestibility of fresh grass silages also could be predicted with good accuracy by NIRS. Practically, it was important to consider the digestibility of a wide range of components in silages such as DM and NDF digestibility considered in this study, and these may be significant in formulating diets for ruminants. For instance, Moe and Carr (1985) and Van Waes et al. (1997) derived good calibrations of in vitro DM and OM digestibility for dried ground maize silages. Meanwhile, the determined parameter digestibility always has large errors associate with the additional error of animal variability coupled with the error of laboratory analyses. Hence NIRS predictions for digestibility were not expected to be as accurate as for chemical compositions. However because of different samples types, statistical approaches and presentation techniques, comparisons across studies are difficult. Kjos (1990) using NIRS on dried herbage samples $\left(60^{\circ} \mathrm{C}, 48 \mathrm{~h}\right)$, with a sample set $(\mathrm{n}=36)$ and $\mathrm{LAB}$-determined in vitro dry matter digestibility reported a mean SEP of $4.53 \%$ and $\mathrm{r}^{2}$ of 0.68 . This was comparable with the present study $(n=35)$ with a mean SEP of $4.24 \%$ and $r^{2}$ of 0.83 . 
Concerning the RSD value, the predictions were good for DM digestibility, the RSD values were 8.25 and $11.26 \%$ for dried and fresh samples, respectively. As for NDF digestibility, the RSD values were clearly higher, being 22.87 and $23.50 \%$ for dried and fresh samples. The bias values of DM digestibility of either dried or fresh samples were negative, which implied that the NIRS values of DM digestibility of silages were greater than the chemical values on the whole. However, the NIRS values of NDF digestibility of silage samples were all lower than the chemical values, while its bias value was positive.

Table 6. The test statistics of validation for the digestibility of silage samples

\begin{tabular}{|c|c|c|c|c|c|c|c|c|c|c|}
\hline \multirow{2}{*}{$\begin{array}{l}\text { Digestibility } \\
\%\end{array}$} & \multicolumn{5}{|c|}{ Dried samples } & \multicolumn{5}{|c|}{ Fresh samples } \\
\hline & $\mathrm{F}$ & $\mathrm{F}_{0.01}$ & $\left|t_{a}\right|$ & $\left|t_{b}\right|$ & $\mathrm{t}_{0.05}$ & $\mathrm{~F}$ & $\mathrm{~F}_{0.01}$ & $\left|t_{a}\right|$ & $\left|t_{b}\right|$ & $\mathrm{T}_{0.05}$ \\
\hline $\mathrm{DM}$ & 160.65 & 7.49 & 0.4602 & 0.2278 & 2.0345 & 67.50 & 7.49 & 0.6142 & 0.7173 & 2.0345 \\
\hline $\mathrm{NDF}$ & 59.92 & 7.49 & 0.5228 & 0.1051 & 2.0345 & 51.27 & 7.51 & 1.3899 & 1.2855 & 2.0369 \\
\hline
\end{tabular}

Table 6 shows the F-test and t-test statistics of validation for the digestibility of silage samples. The ability of NIRS to predict the digestibility of silage is warranted, while the F values of digestibility of DM and NDF were all greater than $\mathrm{F}_{0.01}$, and the $\left|\mathrm{t}_{\mathrm{a}}\right|$ and $\left|\mathrm{t}_{\mathrm{b}}\right|$ values were all lower than $\mathrm{t}_{0.05}$.

\section{CONCLUSIONS}

This study presented opportunities for the NIRS technique to characterize the dry matter (DM) and NDF digestibility of dried and fresh silage samples in the ruminant feeding. Compared with principial component regression and multivariate linear regression, partial least square technique could produce a better prediction, and the calibrations developed from the combination of smooth and first-order derivative treatment were mostly acceptable. The accuracy of determination of dried samples was better than that of fresh samples for DM digestibility but similar for NDF digestibility. Although the number of samples used in the present study was enough to test the ability of NIRS to predict these kinds of digestibility, maybe a broader population could be used to improve the robustness of these equations.

\section{REFERENCES}

AOAC, 1990. Association of Official Analytical Chemists, Official Methods of Analysis. 15th Edition. Washington, DC

Baker C.W., Givens D.I., Deaville E.R., 1994. Prediction of organic matter digestibility in vivo of grass silage by near infrared reflectance spectroscopy: Effect of calibration method, residual moisture and particle size. Anim. Feed Sci. Tech. 50, 17-26 
Barber D.D., Givens D.I., Kridis M.S., Offer N.W., Murray I., 1990. Prediction of the organic matter digestibility of grass silage. Anim. Feed Sci. Tech. 28, 115-128

Clancy M.J., Wilson R.K., 1966. Development and application of a new chemical method for predicting the digestibility and intake of herbage samples. In: Proceedings of Xth International Grassland Congress, Helsinki, pp. 445-453

De Boever J.L., Cottyn B.G., Buysse F.X., Wainman F.W., Vanacker J.M., 1986. The use of an enzymatic technique to predict digestibility, metabolizable and net energy of compound feedstuffs for ruminants. Anim. Feed Sci. Tech. 14, 203-214

De Boever J.L., Cottyn B.G., De Brabander D.L., Vanacker J.M., Boucque Ch.V., 1997. Prediction of the feeding value of maize silages by chemical parameters, in vitro digestibility and NIRS. Anim. Feed Sci. Tech. 66, 211-222

De Boever J.L., Vanacker J.M., De Brabander D.L., 2002. Rumen degradation characteristics of nutrients in maize silages and evaluation of laboratory measurements and NIRS as predictors. Anim. Feed Sci. Tech. 101, 73-86

Goedhart P.W., 1990. Comparison of multivariate calibration methods for prediction of feeding value by near infrared reflectance spectroscopy. Neth. J. Agr. Sci. 38, 449-460

Gordon F.J., Cooper K.M., Park R.S., Steen R.W.J., 1998. The prediction of intake potential and organic matter digestibility of grass silages by near infrared spectroscopy analysis of undried samples. Anim. Feed Sci. Tech. 70, 339-351

Kjos N.P., 1990. Evaluation of the feeding value of fresh forages, silage and hay using near infrared reflectance analysis (NIR). II. Effects of drying procedure, type of mill and particle size. Norw. J. Agr. Sci. 4, 321-330

Liu X., Han L.J., 2006. Evaluation of near-infrared reflectance spectroscopy (NIRS) for predicting chemical composition of straw silage. J. Anim. Feed Sci. 15, 329-336

Mehrez A.Z., Ørskov E.R., 1977. A study of the artificial nylon bag technique for determining the digestibility of feeds in the rumen. J. Agr. Sci. 88, 645-650

Melchinger A.E., Schmidt G.A., Geiger H.H., 1986. Evaluation of near infrared reflectance spectroscopy for predicting grain and stover quality traits in maize. Plant Breed. 97, 20-29

Menke K.H., Raab L., Salewski A., Steingass H., Fritz D., Schneider W., 1979. The estimation of the digestibility and metabolizable energy content of ruminant feeding stuffs from the gas production when they are incubated with rumen liquor in vitro. J. Agr. Sci. 93, 217-222

Moe A.J., Carr S.B., 1985. Laboratory assays and near-infrared reflectance spectroscopy for estimates of feeding value of corn silage. J. Dairy Sci. 68, 2220-2226

Norris K.H., Barnes R.F., Moore J.E., 1976. Predicting forage quality by infrared reflectance spectroscopy. J. Anim. Sci. 43, 889-897

Tilley J. M. A., Terry R. A., 1963. A two-stage technique for the in vitro digestion of forage crops. J. Brit. Grassl. Soc. 18, 104-111

Van Soest P.J., Robertson J.B., Lewis B.A., 1991. Methods for dietary fibre, neutral detergent fibre and nonstarch polysaccharides in relation to animal nutriation. J. Dairy Sci. 74, 3583-3597

Van Waes J., Carlier L., Van Waes C., Van Bockstaelle E., 1997. Evaluation of quality characteristics in official trials with silage maize varieties in Belgium. Neth. J. Agr. Sci. 45, 277-289 